\title{
Syndromic Management of Female Sexually Transmitted Infections at Primary Care Level in Tunisia (Monastir 2007-2017)
}

wafa Dhouib ( $\nabla$ wafa.dhouib20@yahoo.fr)

Department of Epidemiology and Preventive Medicine, University ofMonastir, Tunisia https://orcid.org/0000-0001-8886-9824

Imen Zemni

Department of Epidemiology and Preventive Medicine, University ofMonastir, Tunisia

\section{Meriem Kacem}

Department of Epidemiology and Preventive Medicine, University ofMonastir, Tunisia

\section{Cyrine Bennasrallah}

Department of Epidemiology and Preventive Medicine, University ofMonastir, Tunisia

\section{Manel Ben Fredj}

Department of Epidemiology and Preventive Medicine, University of Monastir, Tunisia

\section{Hela Abroug}

Department of Epidemiology and Preventive Medicine, University ofMonastir, Tunisia

\section{Samia Grira}

The regional direction of primary health of Monastir, Tunisia

\section{Maha Mastouri}

Microbiology laboratory ,Monastir, Tunisia

\section{Asma Belguith Sriha}

Department of Epidemiology and Preventive Medicine, University of Monastir, Tunisia

\section{Research}

Keywords: Sexually Transmitted Diseases, Vaginal Discharge, Chlamydia trachomatis,Neisseria gonorrhoeae,Syphilis,Trichomonasvaginalis,Gardnerellavaginalis

Posted Date: August 13th, 2020

DOI: https://doi.org/10.21203/rs.3.rs-55572/v1

License: (c) (1) This work is licensed under a Creative Commons Attribution 4.0 International License. Read Full License 


\section{Abstract}

Background: In the world as in North Africa,Sexually Transmitted Infections (STIs) are a public health problem especiallyfor reproductive-age women.Since the quantification of the prevalence of STIs is important for the planning of interventions and the promotion of resources, it is necessary to have current data to evaluate the situation in the Maghreb and to give the answer as to the possibility of reaching the desired WHO goal of ending STIs epidemics as a public health concerns by 2030.The aim of this study was to determine the prevalence and trend of STIs during 11 yearsin Tunisia (2007-17).

Methods: We conducted a descriptive cross-sectional study including all women with STIs diagnosed with the syndromic approach in all basic health care centers of the Governorate of Monastir (Tunisia) from 2007 to 2017.Syndromes included, Pelvic Pain (PP),Vaginal Discharge (VD)and Genital Ulceration (GU).

Results: We analyzed 40388 cases of genital infection with a crude prevalence rate and age standardized prevalence rate of 13.93/ 1000 inh and 72.38/ 1000 respectively.The prevalence rate was relatively high and showed a positive trend over 11 years for all age groups and syndromes. VD was the most common syndrome with a CPR of $11.7 / 1000$. For all syndromes, women of childbearing age(20 to 39 years) were the most affected age group $(p<0.05)$.

\section{Conclusion:}

Our results were consistent with the global evidence, suggesting a focus on primary prevention reinforcement and STIs surveillance system improving in North Africa countries to achieve the World health organization goalof ending STIs epidemics by 2030.

\section{Plain English Summary:}

Globally, Sexually Transmitted Infections (STIs) are a public health problem being one of the leading causes of morbidity and mortality. The surveillance system of STIs in developing countries is based on a syndromic approach.This study described the prevalence and trend of STIs in women consulting in all basic health care centers of the Governorate of Monastir (Tunisia) from 2007 to 2017. Syndromes included, Pelvic Pain (PP), Vaginal Discharge (VD) and Genital Ulceration (GU). In reviewing the 40388 cases, the results showed that the prevalence of Stis was relatively high and showed a positive 11-year trend for all age groups and symptoms. VD and especially vaginosis was the most common recorded syndrome. Women of childbearing age were the most affected age group.

To achieve the World health organization goal of ending STIs epidemics by 2030 ,several measures should be reinforced such as additional preventive interventions, prompt identification, correct treatment and partner tracing to stop the spread of these infections.

\section{Background}


Around the world, Sexually Transmitted Infections (STIs) are a public health problem being one of the leading causes of morbidity and mortality. World Health Organization's(WHO) 2012 and 2016 estimates of the global prevalence and incidence of curable STI (chlamydia, gonorrhoea, trichomoniasis, and syphilis) in adults remain high, with nearly one million new infections each day $(1,2)$.ST Is have a carcinogenic effect in cervical cancer and a strong correlation between their spread and HIV transmission leading for many sequelae and complications disproportionately affecting reproductive-age women and children (3). WHO implemented the first (2006-2015) and the second (2016-2021) strategy on STIs and responses around the world with the goal of ending STIs epidemics as a public health concerns by 2030 $(4,5)$. In general, low- and middle-income countries (LMICs) like North African and Maghreb countries have higher estimated burdens of STIs than do high-income countries (HICs) (2). In these countries, STIs diagnostic tests are largely unavailable, expensive and technically demanding on microbiological surveillance systems, so that, surveillance of clinical syndroms called syndromic approach is easier to establish in public health and for all patients. Although this approach according to the WHO guidelines obtain the highest marks in terms of development rigor with ongoing training every two years and being the surveillance system that can best represent the epidemiology of STIs in general population, they may result in an underestimated burden due to asymptomatic cases and moderate specificity and sensitivity(6-8).

In the Maghreb, most studies have focused on the key population and women requesting abortion whose criteria for diagnosing STIs were based on laboratory results (endocervical, urine and vaginal sample)(913). Only, few studies used the data from clinical surveillance to establish the trend and prevalence of some curable STIs in the general population $(14,15)$.

Since the quantification of the prevalence of STIs is important for the planning of interventions and the promotion of resources, it is necessary to have current data to evaluate the situation in the Maghreb and more specifically in Tunisia and to give the answer as to the possibility of reaching the desired objective by WHO for 2030 .

The aim of this study was to determine the prevalence and trend of STIs among women by syndromes during eleven-years in the governorate of Monastir and to evaluate the effectiveness of syndromic management approach to reach the 2030 WHO goals.

\section{Methods}

Study design: We conducted a descriptive cross sectional study including all female cases of STIs from January 1, 2007 to December 31, 2017.

\section{Setting:}

The governorate of Monastir is situated in the coastal region of Tunisia. In 2014, the population of Monastir represented $4.99 \%$ of the Tunisian population (16). In 2015, The total number of Basic health centers (BHC) in the governorate of Monastir was 101(17).From January 1, 2007 to December 31, 2017, 
all women consulting in $\mathrm{BHC}$ for sexual symptoms were diagnosed and treated according to the WHO syndromic approach summarized in flowcharts (clinical algorithm).

The components of case management included: taking history, examination, correct diagnosis, early and effective treatment, advice on sexual behaviour, promotion and/or provision of condoms. All STIs cases diagnosed by the syndromic approach were registered by the physicians or midwifes of each BHC prospectively in a form that was addressed to the regional direction of primary health at the end of each month and recorded on "epi-info" software.

\section{Participants:}

All women in all age groups who consulted the midwives or physicians of each $\mathrm{BHC}$ in Monastir governorate for sexual symptoms and diagnosed by the syndromic approach from January 1, 2007 to December 31, 2017 were included in the study. Other STIs cases which were not diagnosed by the syndromic approach such as vesicular lesions (herpes), chancroid and genital warts were not included in this study.To reach the homogenous and generalizable data, patients who lived in other governorate were excluded from the study.

Variables: Data included variables related to age,sex,consultation date and diagnosis.

WHOdefined (chlamydia, gonorrhoea, trichomoniasis, and syphilis) as curable STI .

The syndromic approach interests these four STIs presented cilically by four symptoms: Pelvic Pain (PP), Vaginal Discharge (VD), Genital Ulceration (GU) and Ureteral Discharge (UD) for men. VD include cervicitis, vaginitis and vaginosis whose symptoms are respectively discharge of muco-pus through the cervix, smelly fluid vaginal discharge and non-specific vaginal discharge (thicker, greenish, smelly).For each syndrome, there are well defined infectious agents incriminated in its symptomatology (Box1).

\section{Measurement:}

The crude prevalence rate (CPR) was calculated based on Tunisian National Institute of Statistics data and was expressed as the number per 1000 inhabitants(/1000inh)(18). The average population was calculated as follows: ((the sum of estimated female population each year) /11) (18). The agestandardized prevalence rate (ASR) per 1000 person-years was calculated using the world standard population according to the WHO statement of 2013(19).

Statistical analysis: Data were verified and analyzed using IBM SPSS Statistics version 22.0 software (IBM Corp., Armonk, NY, USA). Categorical variables (age group) were recorded as numbers and percentages.Linear regression was used to calculate the slope ' $b$ ' of the least-squares line for estimating the trends in notified disease according to sex and age group. A p-value of $<0.05$ was considered statistically significant. 
Ethical considerations: The study was conducted under Good Clinical Practice conditions and according to ethical standards collections. Data collection and analysis were labelled accordingly to maintain anonymity. This study analyzed surveillance system data, does not require ethical approval.

\section{Results}

\section{Prevalence of sexually transmitted infections related syndromes:}

During 11 years, 40388 cases of female genital infections were diagnosed by syndromic approach in $\mathrm{BHC}$ in Monastir governorate. A mean of 3671 cases/year in Monastir, we estimated 73567 cases /year in Tunisia. ASR was 72.38/1000 inh. Overall, the CPR was 13.93/1000 inh being the highest (160.23/1000 inh) in the 30-39 age group. The VD was the most common syndrome (a CPR of 11.7/1000 inh) and especially vaginosis with a CPR of 9.07/1000 inh (Table 1).

\section{Distribution of each syndrome by age group:}

In all age groups the VD was the most frequent syndrome $(p<0.05)($ Fig 1$)$. For all syndromes, the age group mostly affected was that ranging from 20 to $39(p<0.05)$ (Table2).

\section{Chronological study during 11 years:}

The distribution of syndromes by years showed that the highest rate was observed in 2009 with a number of 4996 (CPR =19.96/ $1000 \mathrm{inh}$ ). The lowest rate was recorded in 2012 with 2521 cases (9.39/ $1000 \mathrm{inh}$ ). We established a positive trend for all syndroms $\left(b=139.396 ; r=0.469 ; P<10^{-3}\right)$.All age groups had a positive trend. The age groups with the highest growth rate were those aged 20 to 39 and 40 to 49 in 11 years with standardized coefficient of $65.27(r=0.39 ; p<0.05)$ and $48.13(r=0.538 ; p<0.05)$ respectively (fig 2).

Cases of cervicitis, vaginitis, vaginosis, PP and GU increased over time especially for age group of 20-39 years with respectively $(b=3.09 ; r=0.501 ; p<0.05)$ and $(b=3.91 ; r=0.12 ; p<0.05)$ and $(b=40.58 ; r=0.384$; $p<0.05)$ and $(b=15.087 ; r=0.520 ; p<0.05)$ and $(b=2.293 ; r=0.495 ; p<0.05)$ respectively (fig 3$)$.

\section{Discussion}

\section{Key results.}

The prevalence rate of STIs among women diagnosed with the syndromic approach was relatively high and showed a positive trend over 11 years for all age groups and symptoms. VD and especially vaginosis was the most common recorded syndrome. Women of childbearing age were the most affected age group.

\section{Limitations}


STIs Surveillance at primary health care level was based on syndromic data and not on biological tests. Since each symptom has multiple potential agents, this study based on syndromic data cannot provide accurate statistics on the frequency of STI pathogens. In fact, according to studies conducted in Tunisia and a prospective observational cohort study in South Africa $(6,7,20)$, syndromic approach diagnosis had a low sensitivity and specificity which suggests that the large number of STIs such as VD detected in our study may be largely underestimated and that asymptomatic cases could only be diagnosed by an appropriate biological tests. On the other hand, many cases of VD are not caused by sexually transmitted infections such as cervical ectopy, foreign bodies, retained tampon, vulval dermatitis, non-sexually transmitted infection like some bacterial vaginosis and candida infections $(21,22)$.

As STIs have the same risk factors as other infections, such as HIV and hepatitis, a contact tracing is needed to investigate cases (23). However, as data collection from the registry of STI surveillance was conducted retrospectively, data available on personal and contact information was not exhaustive to do so.

\section{Interpretation:}

- Predominance of STIs among women of childbearing age:

Globally, 2012 and 2016 estimates of the prevalence and incidence of the four curable STIs (chlamydia, gonorrhea, trichomoniasis and syphilis) remain high among women of reproductive age, consistent with our findings $(1,2,24)$.

\section{- Predominance of vaginal discharge syndrome:}

World estimates have shown that for these four pathogens, Trichomonas Vaginalis is the most frequent in women 5.3\% (95\% uncertainty interval Ul:4.0-7.2) followed by Chlamydia trachomatis 3.8\% (95\%, Ul: 3.3-4.5); gonorrhea 0.9\% (95\% Ul: 0.7-1.1) and syphilis 0.5\% (95\% Ul: 0.4-0.6). The same order of pathogens according to their involvement in STIs was also recorded in the East Mediterranean Region (EMR) with a predominance of Trichomonas Vaginalis: 4.7\% (95\% UI:3.3-6.7) followed by Chlamydia trachomatis 3.8\% (95\% Ul: 2.6-5.4); gonorrhea $0.7 \%$ (95\% Ul: 0.5-1.1) and syphilis $0.7 \%$ (95\% Ul: 0.4-1.0) $(1,2,25)$.These statistics are relatively consistent with our results. In fact, when excluding vaginosis which are in most cases caused by a non sexually transmetted pathogens "Gardnerella vaginalis"(26), we find that vaginitis (mainly caused by Trichomonas Vaginalis) was the most frequent syndrome followed by pelvic pain and cervicitis (mainly caused by Chlamydia trachomatis and Neisseria gonorrhea) and then by Genital ulceration (syphilis) (Table 1 and 2). However, our results showed lower prevalence rates than those reported in the literature. This discrepancy could be understood by the low sensitivity of syndromic approach to diagnose STIs leading to an underreporting of cases in our study.

In Tunisia, several studies on the epidemiological characteristics of sexually transmitted infections in women had concluded to a high prevalence of VD and the pathogen Chlamydia trachomatis in those of reproductive age $(6,27)$. In Morocco, a 1995-2015 study of reported cases of VD showed that the 
prevalence of Chlamydia trachomatis was 3.8\%; IC95\%[2.1-6.4] and that of Neisseria gonorrhoeae was 0.37\% IC95\%[0.14-1] of (15).A 2019 meta-analysis had shown that Tunisia had a higher prevalence of Chlamydia trachomatis than Morocco and Algeria and highlighted strong evidence of a sub-regional difference with the Horn Africa and North Africa (Tunisia, Morocco, Algeria, Sudan) presenting respectively 6 fold and 5 fold higher odds of syphilis infection than Eastern Middle East and North Africa(MENA)(10) .

The predominance of vaginosis among female consulting for vaginal discharge in our study is concordant with the results of a Meta-Analysis published in 2019 which have shown that general population prevalence of bacterial vaginosis is high globally, ranging from $23 \%$ to $29 \%$ across regions (Middle East and North Africa: 25\%; sub-Saharan Africa: 25\%) $(28,29)$. However, their predominance is not synonymous with their incrimination in STIs, because the most common bacterial vaginosis "Gardnerella vaginalis" is not sexually transmitted bacteria but found naturally in the vagina(26). These vaginosis are endogenous reproductive tract infection resulting from replacement of the normal hydrogen peroxideproducing Lactobacillus sp. in the vagina by high concentrations of anaerobic bacteria, such as Gardnerella vaginalis (30).

\section{- An upward trend in STIS:}

Consist with our findings, WHO prevalence estimates of the four curable STIs among women have shown an overall positive trend from 2012 to 2016 globally and especially in the EMR (25). This trend of declared STIs showed that we are not on the right way to reach 2030 goals of eliminating STIs as a public health problem. It could be explained by,first, the change in lifestyle, sexual behavior and other factors such as addiction which is currently a health problem in Tunisia where illicit substance use among college students represents one of the most complicated social problems(31). Secondly,it could also be due to the low sensitivity of the syndromic approach to detect asymptomatic cases that would be potential sources for infections dissemination.

In conclusion, despite a possible underreporting of STIs cases in this study, the results showed a significant increase in their trend over time. This upward trend of STIs may be the result of a failing primary prevention on which we must act.

\section{Conclusion}

To reach the 2030 goal of eliminating STIs in Maghreb countries, several measures should be reinforced. First, a continuous monitoring of STI prevalence and incidence which is fundamental to design, implement and evaluate STI interventions that is why WHO and its partners are looking at options to improve the quality of future estimates and supporting countries to generate their own national estimates (1).Second, additional preventive interventions including behavioral changes in the use of alcohol and substances and a focus on populations at risk such as sex workers. Third, prompt identification, correct treatment and partner tracing to stop the spread of these infections. 


\section{Abbreviations}

ASR: Age-Standardized Prevalence Rate

BHC Basic Health Centers

CPR: Crude Prevalence Rate

EMR: East Mediterranean Region

GU :Genital Ulceration

HICs :High-Income Countries

HIV: Human Immunodeficiency Virus

LMICs: Low- and Middle-Income Countries

MENA:Middle East and North Africa

PP :Pelvic Pain

STIs :Sexually Transmitted Infections

VD: Vaginal Discharge

WHO: World Health Organization

\section{Declarations}

Ethics approval and consent to participate:

The study was approved by the Ethical Committee of faculty of medicine (Monastir). Data was anonymous.

Consent to publish: Not Applicable

Availability of data and materials:

All data generated or analyzed during this study are included in this published article.

Competing interests :The authors declare that they have no competing interests.

Funding: This study received no financial support.

Authors' Contributions 
WD: Conceptualization, Formal analysis, Methodology,Writing - original draft.

ASB and IZ: design of the work Formal analysis, Methodology, Super- vision and substantively revised the draft.

$\mathrm{MK}, \mathrm{CBN}, \mathrm{MBF}, \mathrm{HA}$ and MM: Formal analysis, interpretation of data and draft revision. SSG: data collection and verification.

All authors agreed to be personally accountable for the author's own contributions, have read and approved the manuscript.

Acknowledgments: The authors thank the team of the regional direction of primary health, department of Epidemiology and Preventive Medicine at the university hospital of Monastir. Authors offer this paper to our eminent Professor Soltani Mohamed.

\section{References}

1. Newman L, Rowley J, Vander Hoorn S, Wijesooriya NS, Unemo M, Low N, et al. Global Estimates of the Prevalence and Incidence of Four Curable Sexually Transmitted Infections in 2012 Based on Systematic Review and Global Reporting. PloS One. 2015;10(12):e0143304.

2. Vos T, Abajobir AA, Abate KH, Abbafati C, Abbas KM, Abd-Allah F, et al. Global, regional, and national incidence, prevalence, and years lived with disability for 328 diseases and injuries for 195 countries, 1990-2016: a systematic analysis for the Global Burden of Disease Study 2016. The Lancet. 16 sept 2017;390(10100):121159.

3. Karim S, Souho T, Benlemlih M, Bennani B. Cervical Cancer Induction Enhancement Potential of Chlamydia Trachomatis: A Systematic Review. Curr Microbiol. déc 2018;75(12):166774.

4. WHO | Global strategy for the prevention and control of sexually transmitted infections: 2006 - 2015 [Internet]. WHO. [cité 23 janv 2019]. Disponible sur:

http://www.who.int/reproductivehealth/publications/rtis/9789241563475/en/

5. WHO | Global health sector strategy on Sexually Transmitted Infections, 2016-2021 [Internet]. WHO. [cité 23 janv 2019]. Disponible sur: http://www.who.int/reproductivehealth/publications/rtis/ghssstis/en/

6. Zribi M, Mansour KB, Abid F, Masmoudi A, Fendri C. Syndromic approach to sexually transmitted infections in Tunisian women: bacteriological validation. Int J STD AIDS. févr 2008;19(2):1124.

7. Ben Aissa-Hamzaoui R, Kouki S, Ben Hamida A, Kechrid A, Gueddana N. [Prevalence of sexually transmitted diseases among pregnant Tunisian women and validation of a clinical algorithm proposed by WHO for the management of sexually transmitted diseases]. Contracept Fertil Sex 1992. nov 1999;27(11):78590. 
8. Dickson C, Arnason T, Friedman DS, Metz G, Grimshaw JM. A systematic review and appraisal of the quality of practice guidelines for the management of Neisseria gonorrhoeae infections. Sex Transm Infect. 2017;93(7):48792.

9. Bourouache M, Mimouni R, Nejmeddine M, Chadli S, Benlmeliani F, Sardi J, et al. The prevalence of syphilis in HIV-seropositive patients: a retrospective study at the regional hospital in Agadir, Morocco. Pan Afr Med J. 2019;33:252.

10. Chemaitelly H, Weiss HA, Smolak A, Majed E, Abu-Raddad LJ. Epidemiology of Treponema pallidum, Chlamydia trachomatis, Neisseria gonorrhoeae, Trichomonas vaginalis, and herpes simplex virus type 2 among female sex workers in the Middle East and North Africa: systematic review and meta-analytics. J Glob Health. déc 2019;9(2):020408.

11. Znazen A, Zribi N, Maazoun L, Khrouf S, Hammami A. Epidemiological features of sexually transmitted infections among women in Tunisia: high prevalence of Chlamydia trachomatis among women requesting abortion. Sex Transm Infect. févr 2013;89(1):56.

12. Bchir A, Jemni L, Saadi M, Milovanovic A, Brahim H, Catalan F. Markers of sexually transmitted diseases in prostitutes in central Tunisia. Genitourin Med. déc 1988;64(6):3967.

13. Gharsallah H, Bom RJM, Bruisten SM, Himschoot M, Frikha-Gargouri O, Hammami A. Identification of a dominant Chlamydia trachomatis strain in patients attending sexual transmitted infection clinic and female sex workers in Tunisia using a high resolution typing method. Infect Genet Evol J Mol Epidemiol Evol Genet Infect Dis. 2016;44:4449.

14. Bennani A, El-Kettani A, Hançali A, El-Rhilani H, Alami K, Youbi M, et al. The prevalence and incidence of active syphilis in women in Morocco, 1995-2016: Model-based estimation and implications for STI surveillance. PloS One. 2017;12(8):e0181498.

15. El-Kettani A, Mahiané G, Bennani A, Abu-Raddad L, Smolak A, Rowley J, et al. Trends in Adult Chlamydia and Gonorrhea Prevalence, Incidence and Urethral Discharge Case Reporting in Morocco over 1995-2015-Estimates Using the Spectrum-Sexually Transmitted Infection Model. Sex Transm Dis. 2017;44(9):55764.

16. Recencement [Internet]. INS. [cité 23 mars 2018]. Disponible sur: http://census.ins.tn/fr/recensement

17. Carte sanitaire - Ministère de la santé publique [Internet]. [cité 1 févr 2019]. Disponible sur: http://www.santetunisie.rns.tn/fr/carte-sanitaire/carte-sanitaire-2011

18. Portail de données de la Tunisie, Analyse de Données [Internet]. [cité 28 janv 2019]. Disponible sur: http://dataportal.ins.tn/fr/DataAnalysis?8xPhnNxdAku94ZDqKTYVfw

19. World (WHO 2000-2025) Standard - Standard Populations - SEER Datasets [Internet]. [cité 23 mars 2018]. Disponible sur: https://seer.cancer.gov/stdpopulations/world.who.html 
20. Mlisana K, Naicker N, Werner L, Roberts L, van Loggerenberg F, Baxter C, et al. Symptomatic vaginal discharge is a poor predictor of sexually transmitted infections and genital tract inflammation in high-risk women in South Africa. J Infect Dis. 1 juill 2012;206(1):614.

21. Spence D, Melville C. Vaginal discharge. BMJ. 1 déc 2007;335(7630):114751.

22. Maleb A, Frikh M, Lahlou YB, Belefquih B, Lemnouer A, Elouennass M. Écoulements vaginaux d'origine infectieuse chez la femme adulte à l'hôpital militaire d'instruction Mohammed V de Rabat (Maroc) : étude de 412 cas. Rev Sage-Femme. 1 juin 2018;17(3):1226.

23. Sellami A, Kharfi M, Youssef S, Zghal M, Fazaa B, Mokhtar I, et al. [Epidemiologic profile of sexually transmitted diseases (STD) through a specialized consultation of STD]. Tunis Med. mars 2003;81(3):1626.

24. Chesson HW, Mayaud P, Aral SO. Sexually Transmitted Infections: Impact and Cost-Effectiveness of Prevention. In: Holmes KK, Bertozzi S, Bloom BR, Jha P, éditeurs. Major Infectious Diseases [Internet]. 3rd éd. Washington (DC): The International Bank for Reconstruction and Development / The World Bank; 2017 [cité 9 janv 2020]. Disponible sur: http://www.ncbi.nlm.nih.gov/books/NBK525195/

25. Rowley J, Vander Hoorn S, Korenromp E, Low N, Unemo M, Abu-Raddad LJ, et al. Chlamydia, gonorrhoea, trichomoniasis and syphilis: global prevalence and incidence estimates, 2016. Bull World Health Organ. 1 août 2019;97(8):548-562P.

26. Morris MC, Rogers PA, Kinghorn GR. Is bacterial vaginosis a sexually transmitted infection? Sex Transm Infect. 1 févr 2001;77(1):638.

27. Znazen A, Zribi N, Maazoun L, Khrouf S, Hammami A. Epidemiological features of sexually transmitted infections among women in Tunisia: high prevalence of Chlamydia trachomatis among women requesting abortion. Sex Transm Infect. févr 2013;89(1):5656.

28. Javed A, Parvaiz F, Manzoor S. Bacterial vaginosis: An insight into the prevalence, alternative treatments regimen and it's associated resistance patterns. Microb Pathog. févr 2019;127:2130.

29. Peebles K, Velloza J, Balkus JE, McClelland RS, Barnabas RV. High Global Burden and Costs of Bacterial Vaginosis: A Systematic Review and Meta-Analysis. Sex Transm Dis. 2019;46(5):30411.

30. WHO | Guidelines for the management of sexually transmitted infections [Internet]. WHO. World Health Organization; [cité 20 mai 2020]. Disponible sur: https://www.who.int/hiv/pub/sti/pub6/en/

31. Chekib Z, Zammit N, Manel L, Menel M, Elghardallou M, Jihen S, et al. Illicit substance use among Tunisian college students: prevalence and risk factors. Int J Adolesc Med Health. 25 mai 2017;30(6).

\section{Tables}


Table 1: Crude and age standardized prevalence ratesof woman, by age groups and syndromes of sexual transmitted infectionsdiagnosed by syndromic approach in Monastir (2007-2017)

\begin{tabular}{|llll|}
\hline & Cases(\%)(11 years) & CPR * & ASR* \\
\hline Overall & $40388(100)$ & 13.93 & 72.38 \\
\hline Age groups (Years) & & & \\
\hline $0-4$ & $6(0.0)$ & 0.12 & \\
\hline $5-14$ & $77(0.2)$ & 1.88 & 23.28 \\
\hline $15-19$ & $1060(2.6)$ & 76.08 \\
\hline $20-29$ & $9986(24.7)$ & 160.23 \\
\hline $30-39$ & $15318(37.9)$ & 146.47 \\
\hline $40-49$ & $10268(25.4)$ & 71.47 \\
\hline$\geq 50$ & $3673(9.1)$ & \\
\hline Syndroms & & 2.11 \\
\hline PP & $6126(15.2)$ & 0.11 \\
\hline GU & $336(0.8)$ & 11.70 \\
\hline VD & $33926(84.0)$ & 0.37 \\
\hline Cervicitis & $1099(2.7)$ & 2.24 \\
\hline Vaginitis & $6519(16.1)$ & 9.07 \\
\hline Vaginosis & $26308(65.1)$ & \\
\hline
\end{tabular}

*: per 1000 inhabitants; CPR: crud prevalence rate; ASR: age standardized rate; PP :Pelvic Pain ; VD: Vaginal Discharge; GU: Genital Ulceration

Table 2: distribution of STIs syndrome by age groups in Monastir (2007-2017) 


\begin{tabular}{|lllllll|}
\hline \multicolumn{1}{|c}{ AGE } & $0-19$ & $20-39$ & $40-49$ & $\geq 50$ & Overall & $\mathrm{p}$ \\
GROUPS & $\mathrm{n} \mathrm{( \% )}$ & $\mathrm{n}(\%)$ & $\mathrm{n} \mathrm{( \% )}$ & $\mathrm{n}(\%)$ & $\mathrm{n}(\%)$ & \\
Syndromes & & & & & & \\
\hline PP & $186(3.0)$ & $3818(62.8)$ & $1642(26.8)$ & $480(7.8)$ & $6126(100)$ & $<0.05$ \\
\hline GU & $3(0.9)$ & $213(63.4)$ & $80(23.8)$ & $40(11.9)$ & $336(100)$ & 0.038 \\
\hline VD & $954(2.8)$ & $21273(62.7)$ & $8546(25.2)$ & $3153(9.3)$ & $33926(100)$ & $<0.05$ \\
\hline Cervicitis & $31(2.8)$ & $81.7(74.3)$ & $214(19.5)$ & $37(3.4)$ & $1099(100)$ & $<0.05$ \\
\hline Vaginitis & $132(2.0)$ & $4467(68.5)$ & $1491(22.9)$ & $429(6.6)$ & $6519(100)$ & $<0.05$ \\
\hline Vaginosis & $791(3.0)$ & $15989(60.8)$ & $6841(26)$ & $2687(10.2)$ & $26308(100)$ & $<0.05$ \\
\hline
\end{tabular}

PP :Pelvic Pain ; VD: Vaginal Discharge ; GU: Genital Ulceration

Figures

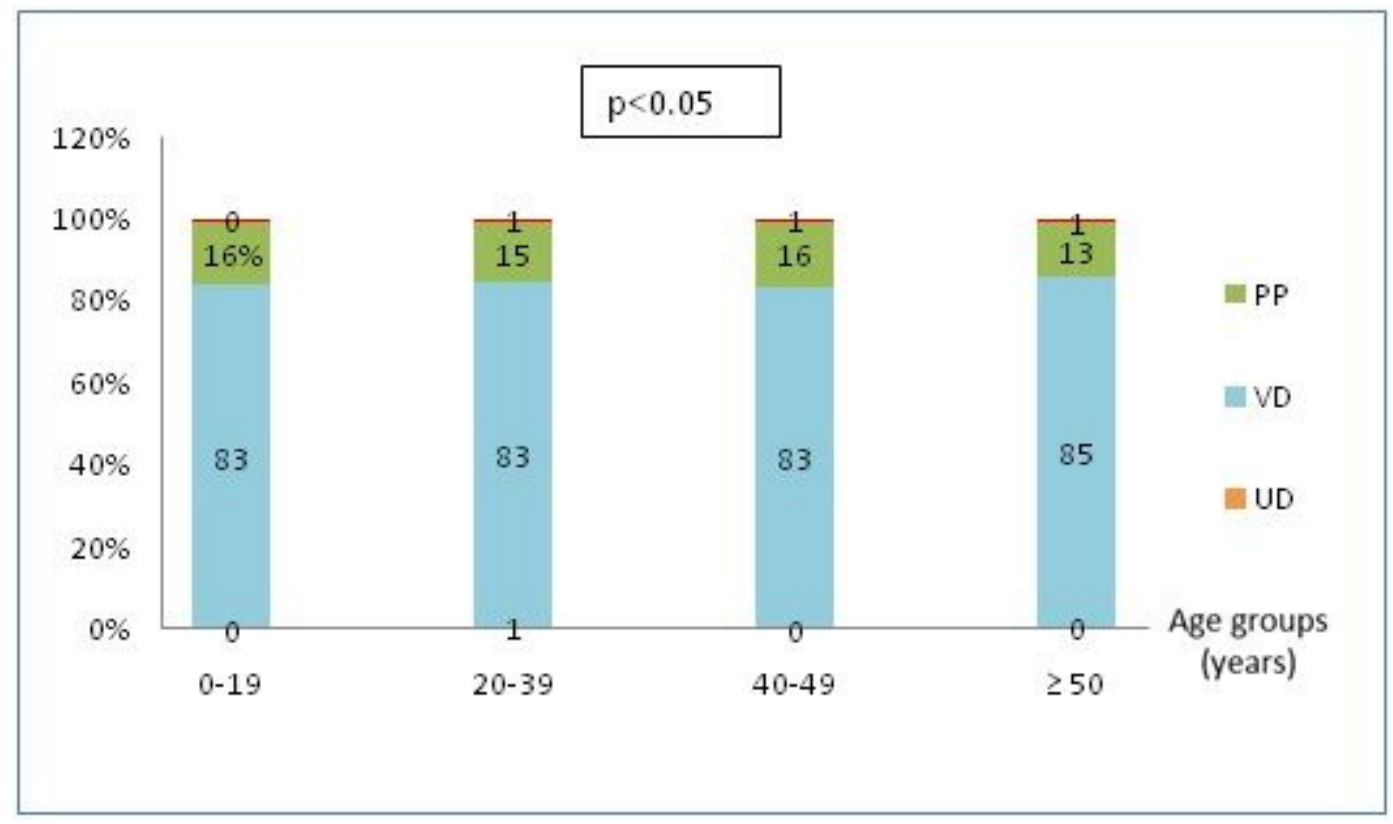

Figure 1

Distribution of syndromic approach according to age groups Monastir (2007-2017) PP :Pelvic Pain ; VD: Vaginal Discharge; GU: Genital Ulceration 




Figure 2

Trends of STls by age groups (2007-2017) in Monastir. 

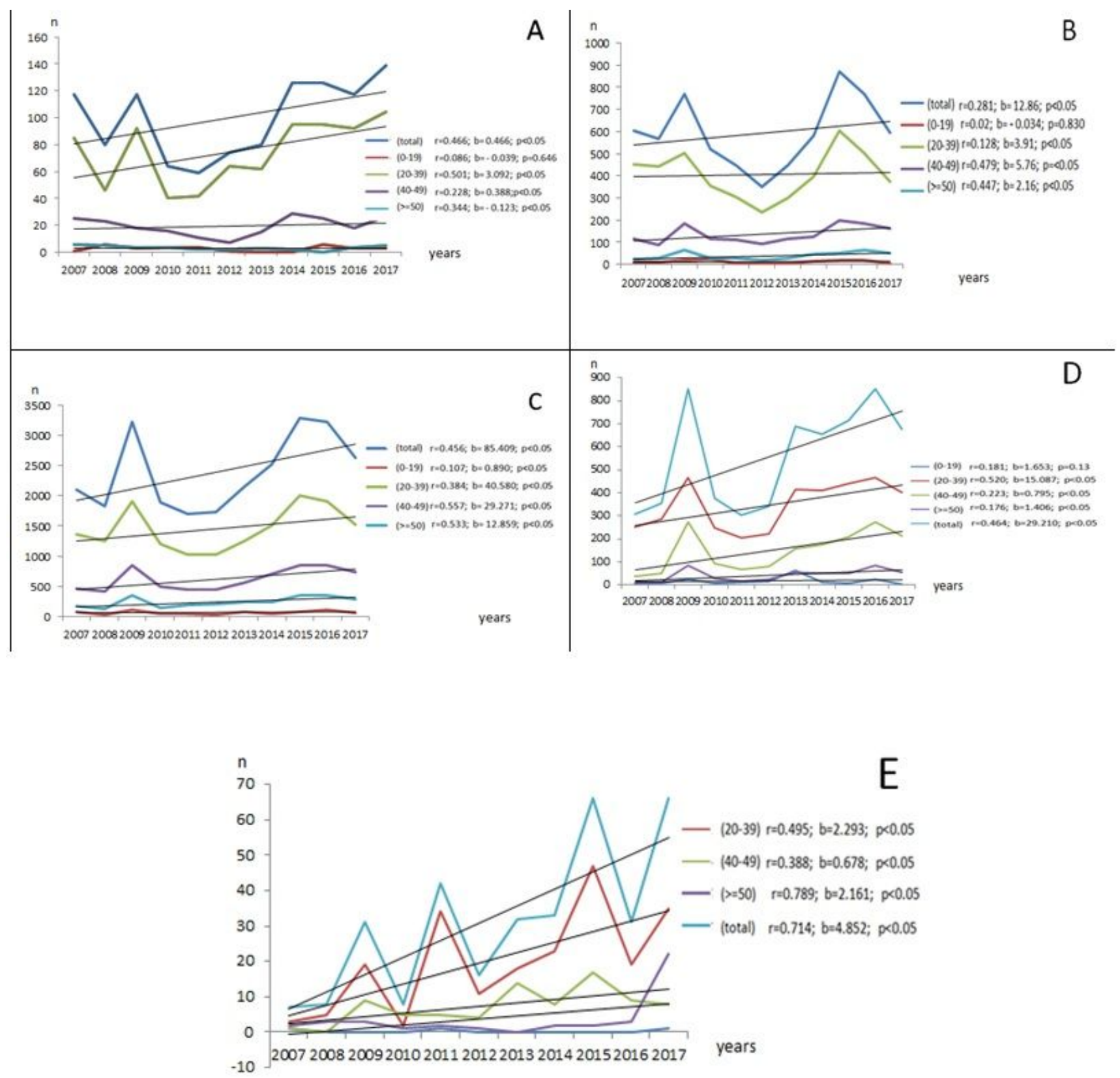

\section{Figure 3}

Distribution of each STIs by years and age groups (2007-2017) in Monastir A :cervicitis : for age group of 20-39 years a positive trend $(r=0.501 ; b=3.092 ; p<0.05)$ was established $B$ :vaginitis :for age group of 2039 years a positive trend $(r=0.128 ; b=3.91 ; p<0.05)$ was established $C$ : vaginosis : for age group of 20-39 years a positive trend $(r=0.384 ; b=40.580 ; p<0.05)$ was established $D$ : pelvic pain: for age group of 20-39 years a positive trend $(r=0.520 ; b=15.087 ; p<0.05)$ was established E: Genital ulceration: for age group of 20-39 years a positive trend $r=0.495 ; b=2.293 ; p<0.05$ was established 